\title{
SINGLE COPY DNA HOMOLOGIES IN ATRIPLEX. II. HYBRID THERMAL STABILITIES AND MOLECULAR PHYLOGENY*
}

\author{
HEATHER S. BELFORD $\dagger$ and WILLIAM F. THOMPSON \\ Department of Plant Biology, Carnegie Institution of Washington, \\ Stanford, CA 94305, U.S.A.
}

Received 21.vii.80

\section{SUMMARY}

\begin{abstract}
Single copy DNA sequence homologies were measured by interspecific molecular hybridization and thermal denaturation techniques for eight species of the genus Atriplex and spinach (Spinacia oleracea). Thermal stability profiles for Atriplex interspecific hybrids indicated more base pair mismatch than has been observed in most previously reported intrageneric comparisons of animal DNA. On the assumption that sequence divergence by base substitution is proportional to the time which has elapsed subsequent to speciation, the data are interpreted as indicating that lines leading to many modern Atriplex species probably originated during a single period of rapid speciation. This group includes $\mathrm{C}_{3}$ and $\mathrm{C}_{4}$ photosynthetic types from both subgenera. Thus the molecular data do not support the classical subgeneric distinction, and it is no longer necessary to postulate a polyphyletic origin for $\mathrm{C}_{4}$ photosynthesis within Atriplex.
\end{abstract}

\section{INTRODUCTION}

ATRIPLEX is a cosmopolitan angiosperm genus of the family Chenopodiaceae, comprised of halophytic species native to many varied marginal and/or extreme environments (Osmond et al., 1980). The phylogenetic relationships within the genus have recently come under review with the discovery that it includes species with both $\mathrm{C} 3$ and $\mathrm{C} 4$ photosynthetic pathways (Björkman et al., 1973). The most recent phylogenetic evaluation (Hall and Clements, 1923) was based solely on morphological characteristics and suggests that Atriplex should be split into two subgenera. Combination of this scheme with modern physiological data leads to the conclusion that $\mathrm{C} 4$ species have evolved on at least two occasions, once in each subgenus. While a polyphyletic origin for $\mathrm{C} 4$ photosynthesis is widely accepted for angiosperms in general it might be viewed as improbable within a group so closely related as a single genus.

In addition to the question of $\mathrm{C} 4$ species origin, there is also the question of how closely various Atriplex species are related. Hall and Clements (1923) describe an order of branching in their morphologically-based phylogenetic tree. The length of branches, or the interspecific divergence distances, are not specified although a gradually reticulating evolutionary pattern is implied. Experimental breeding programs were undertaken to

* This research was supported by NSF grant DEB76-83405 and funds from the Carnegie Institution of Washington. This paper is publication number 718 from the Department of Plant Biology, and is based on a portion of a dissertation submitted by H.S.B. in partial fulfilment of the Ph.D requirements in the Department of Botany, University of Massachusetts, Amherst.

+ Current address: Department of Biochemistry, Boston University, 80 E. Concord St., Boston MA 02118, U.S.A. 
clarify these relationships (Nobs, 1976). However, with a few exceptions, mating barriers were strong and sexual crosses failed to even produce seed. Thus a molecular approach to measuring evolutionary relationships in Atriplex seemed desirable.

The use of interspecific DNA sequence comparison in phylogenetic studies is based on the assumptions that (1) all sequences are subject to random point mutation, and (2) the fixation rate of random point mutations is constant with respect to time when averaged over the entire genome (for reviews see Kohne, 1970, and Wilson et al., 1977). When a population becomes subdivided into genetically isolated groups, the DNA sequences of each group diverge from those of other subgroups at a constant rate. Thus interspecific sequence divergence should be directly proportional to time subsequent to genetic isolation, and estimates of sequence divergence may provide a kind of molecular clock, indicating (at least in relative terms) the time at which two lineages diverted from a common ancestor. Using molecular hybridization techniques, homologous DNA sequences from two species can be annealed in vitro and the hybrid duplexes subjected to thermal dissociation to reveal the extent to which the base sequences of each species are diverged from one another. For eukaryotes containing significant amounts of repetitive DNA sequences, such sequence divergence estimates should be restricted to single copy sequences. Point mutations can occur in all DNA sequences, including those which belong to repetitive families. Thus there will be sequence divergence among the members of repetitive families within ony one genome, obscuring any difference between different genomes. We have argued previously (Stein et al., 1979) that interspecific differences in repeated DNA hybrids must arise from events other than random base substitution (e.g., amplification or reamplification) and thus cannot be expected to reflect divergence time. However, as pointed out by Kohne (1970), hybrids formed from single copy DNA should be composed only of sequences descended from the same ancestral sequence; such hybrids should thus provide a valid measure of the extent to which base substitution has occurred since separation of any two lineages.

For the present study eight species were chosen to represent diverse placements in the morphologically-based phylogeny (see fig. 1 of Belford and Thompson, 1980). A. hortensis (C3, A. triangularis (C3), A. rosea (C4) and $A$. sabulosa $(C 4)$ were chosen to represent the Hall and Clements subgenus Euatriplex, while $A$. phyllostegia (C3), A. truncata (C4), A. fruticulosa (C4) and $A$. serenana (C4) represent the subgenus Obione. Spinach (Spinacia oleracea, which also belongs to the family Chenopodiaceae) was included to provide an extrageneric comparison. Sequence divergence was measured for all species with respect to each of two references, $\boldsymbol{A}$. serenana and $\boldsymbol{A}$. rosea, permitting construction of a partial matrix of relationships.

In addition to clarification of Atriplex evolutionary relationships, this work was also undertaken to gain information on the extent of sequence divergence among members of an angiosperm genus and between genera of a single angiosperm family. Previous divergence measurements have been made for various animal taxa (Harpold and Craig, 1978; Angerer et al., 1976; Shields and Straus, 1975; Sohn et al., 1975; Rice, 1972; Laird et al., 1969) and among three species of the fern genus Osmunda (Stein et al., 


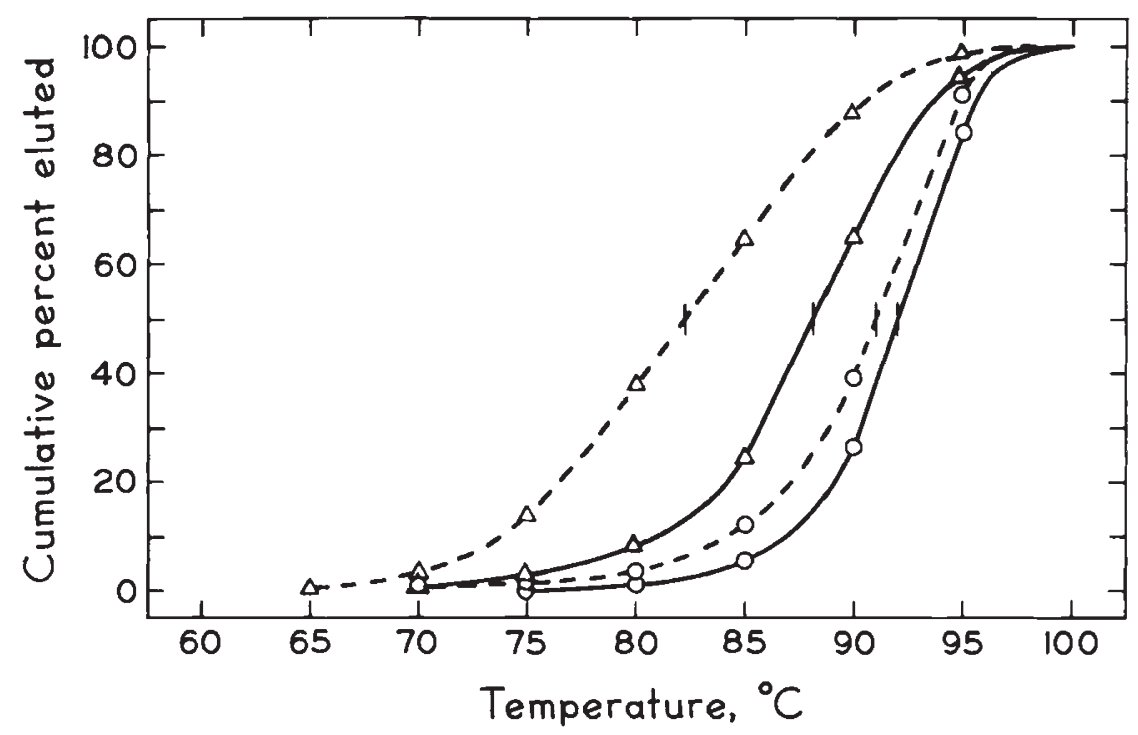

FIG. 1.-Thermal denaturation profiles for native and deaminated $E$. coli DNA in $120 \mathrm{mM}$ and $75 \mathrm{mM}$ PB. $E$. coli DNA which had been partially deaminated to introduce base pair mismatching (Ullman and McCarthy, 1973) was kindly supplied by R. E. Cuellar. Six replicate aliquots were heat-denatured and reassociated to equivalent Cot 200 in $0.6 \mathrm{M} \mathrm{PB}, 0.1 \mathrm{mM} \mathrm{Na}{ }_{2}$ EDTA. After dilution into $120 \mathrm{mM}$ PB and addition of tracer quantities of ${ }^{14} \mathrm{C}$-labelled native $E$. coli DNA of about 250 NTP fragment length, the samples were applied to HAP at $60^{\circ} \mathrm{C}$. Bound DNA was then eluted in 75 or $120 \mathrm{mM} \mathrm{PB}$ by raising the temperature in $5^{\circ} \mathrm{C}$ increments. Symbols: $(\triangle)$, deaminated $E$. coli DNA; (O), ${ }^{14} \mathrm{C}$-labelled native $E$. coli DNA. Dashed lines indicate the thermal denaturation profiles obtained for $120 \mathrm{mM}$ PB elution. Solid lines are profiles resulting from elution with $75 \mathrm{mM}$ PB. $\triangle T_{E}$ values for the deaminated DNA were $8.8^{\circ}$ in $120 \mathrm{mM}$ PB and $3.9^{\circ} \mathrm{C}$ in $75 \mathrm{mM}$ PB. When the same DNAs were melted in the spectrophotometer in $120 \mathrm{mMPB}$ a $\Delta T_{m}$ of $4 \cdot 0^{\circ}$ was obtained from hyperchromicity measurements (R. E. Cuellar, personal communication).

1979). DNA sequence comparisons among Lathyrus species showed that divergence was indeed great enough to be detected among species within an angiosperm genus (Narayan and Rees, 1977).

\section{MATERIALS AND METHODS}

Plant material, DNA purification and single copy sequence preparation were as described (Belford and Thompson, 1980). Deaminated E. coli DNA was kindly supplied by R. E. Cuellar. DNA hybridization mixtures contained unlabeled total DNA as driver, a homologous single copy tracer and a heterologous single copy tracer in a ratio of $1 \mathrm{mg}$ driver to $80,000 \mathrm{cpm}$ ${ }^{14} \mathrm{C}$-tracer and $400,000 \mathrm{cpm}{ }^{3} \mathrm{H}$-tracer. Driver: tracer mass ratios were about 2000:1 and 9000:1 for ${ }^{14} \mathrm{C}$ - and ${ }^{3} \mathrm{H}$-tracers, respectively. Driver and tracer DNAs were dissolved in $600 \mathrm{mM} \mathrm{NaPB}, p \mathrm{H} 6 \cdot 8,0 \cdot 1 \mathrm{mM} \mathrm{Na}_{2}$ EDTA, to a final concentration of $4 \cdot 5-5 \cdot 0 \mathrm{mg} \mathrm{DNA} / \mathrm{ml}$. Aliquots were sealed in disposable glass capillaries, denatured 2-4 minutes in a polyethylene glycol bath at $104-110^{\circ} \mathrm{C}$ and reassociated for the required period in a circulating water bath at $66^{\circ} \mathrm{C}$. The reaction was stopped by immersing the capillaries 
in ice water followed by dilution into chilled $120 \mathrm{mM} \mathrm{NaPB}$. The dilutions were stored on ice or frozen in liquid nitrogen and kept at $-20^{\circ} \mathrm{C}$ until thermal denaturation.

Thermal denaturation of HAP*-bound DNA was performed as described by Britten et al. (1974) except that the elution buffer was $75 \mathrm{mM}$ NaPB. This buffer molarity was chosen after constructing a "window diagram" as described by Martinsen and Wagenaar (1977) to ensure that only single-stranded DNA would be eluted from the HAP between 60 and $100^{\circ} \mathrm{C}$. For each $T_{E}$ determination, triplicate aliquots of reassociated DNAs were warmed to $60^{\circ} \mathrm{C}$ for several minutes, then loaded onto $0.25 \mathrm{ml} \mathrm{HAP}$ columns equilibrated in $120 \mathrm{mM} \mathrm{NaPB}$ at $60^{\circ} \mathrm{C}$. After an initial wash with $120 \mathrm{mM} \mathrm{NaPB}$ to remove any unreassociated or degraded DNA, the HAP columns were equilibrated with $75 \mathrm{mM} \mathrm{NaPB}$ and thermally eluted in $5^{\circ}$ steps. The presence of tracer DNAs was assayed by adjusting all column fractions to $2.5 \mathrm{ml}$ and $120 \mathrm{mM} \mathrm{NaPB}$, and counting in $9.4 \mathrm{ml}$ Triton-X$100 /$ toluene $(1: 2)$ scintillation fluid. The simultaneous use of ${ }^{3} \mathrm{H}$ - and ${ }^{14} \mathrm{C}$-labelled tracers permitted each pair of homologous and heterologous tracer-driver duplexes to be formed in the same solution and analyzed on the same column.

\section{RESUlts}

Historically, it has been standard practice to carry out thermal elution experiments with $120 \mathrm{mM} \mathrm{NaPB}$. However, the results of Martinson and Wagenaar (1977) and our data (Belford, 1979) show that at temperatures above $60^{\circ}$ some mismatched and/or short duplexes with low affinity for HAP can be eluted by $120 \mathrm{mM}$ NaPB before the strands have completely dissociated. Because heterologous hybrids generally contain less well paired and possibly shorter duplex regions than homologous hybrids, premature elution of double strands would affect the apparent thermal stability of heterologous duplexes more than that of homologous duplexes and thus produce anomalously high $\Delta T_{E}$ values. $75 \mathrm{mM} \mathrm{NaPB}$ is near the center of the thermal elution "window" for well matched DNA and thus should minimize double-strand elution artefacts for interspecific hybrids (Martinsen and Wagenaar, 1977).

Thus we believe that our thermal elution data reflect actual thermal stabilities of hybrid duplexes more accurately than similar data obtained with $120 \mathrm{mM} \mathrm{NaPB}$. This view is supported by the results of the experiment illustrated in fig. 1, in which artificially mismatched and control E. coli DNA samples were subjected to thermal elution in either 75 or $120 \mathrm{mM}$ NaPB. The $\Delta T_{E}$ obtained in $75 \mathrm{mM} \mathrm{NaPB}$ was about half that obtained in $120 \mathrm{NaPB}$, and much closer to the $\Delta T_{E}$ measured by optical techniques. Similar $\Delta T_{E}$ ratios were obtained for interspecific hybrid duplexes between single copy tracers and total DNA of several Osmunda species (Stein et al., 1979 , and unpublished data). It is generally assumed that a $1^{\circ} \Delta T_{E}$ in $120 \mathrm{mM} \mathrm{NaPB}$ corresponds to about 1 per cent mismatched base pairs (e.g., Britten et al., 1974; Angerer et al., 1976; Stein et al., 1979). If we accept this assumption, it is reasonable to suppose that the same $\Delta T_{E}$ in $75 \mathrm{mM} \mathrm{NaPB}$ would correspond to about 2 per cent mispairing.

\footnotetext{
* Abbreviations: HAP, hydroxyapatite (Bio Rad HTP, Lot \#16020); NaPB, equimolar $\mathrm{Na}_{2} \mathrm{HPO}_{4}$ and $\mathrm{NaH}_{2} \mathrm{PO}_{4}, p \mathrm{H} 6.8 ; \mathrm{NTP}$, nucleotide pairs; $T_{E}$ temperature at which 50 per cent of the duplex DNA bound to HAP has eluted.
} 


\section{(i) Atriplex thermal denaturation experiments}

Homologous and heterologous tracers were reassociated with excess unlabeled DNA to equivalent $C_{0} t$ values of 880 and 28,000 , bound to HAP, and denatured as described in Methods. In order to eliminate any effects on the melting profiles of contaminating repetitive sequence hybrids or intrastrand (foldback) duplexes in the in vitro labeled tracers, the $C_{0} t 880$
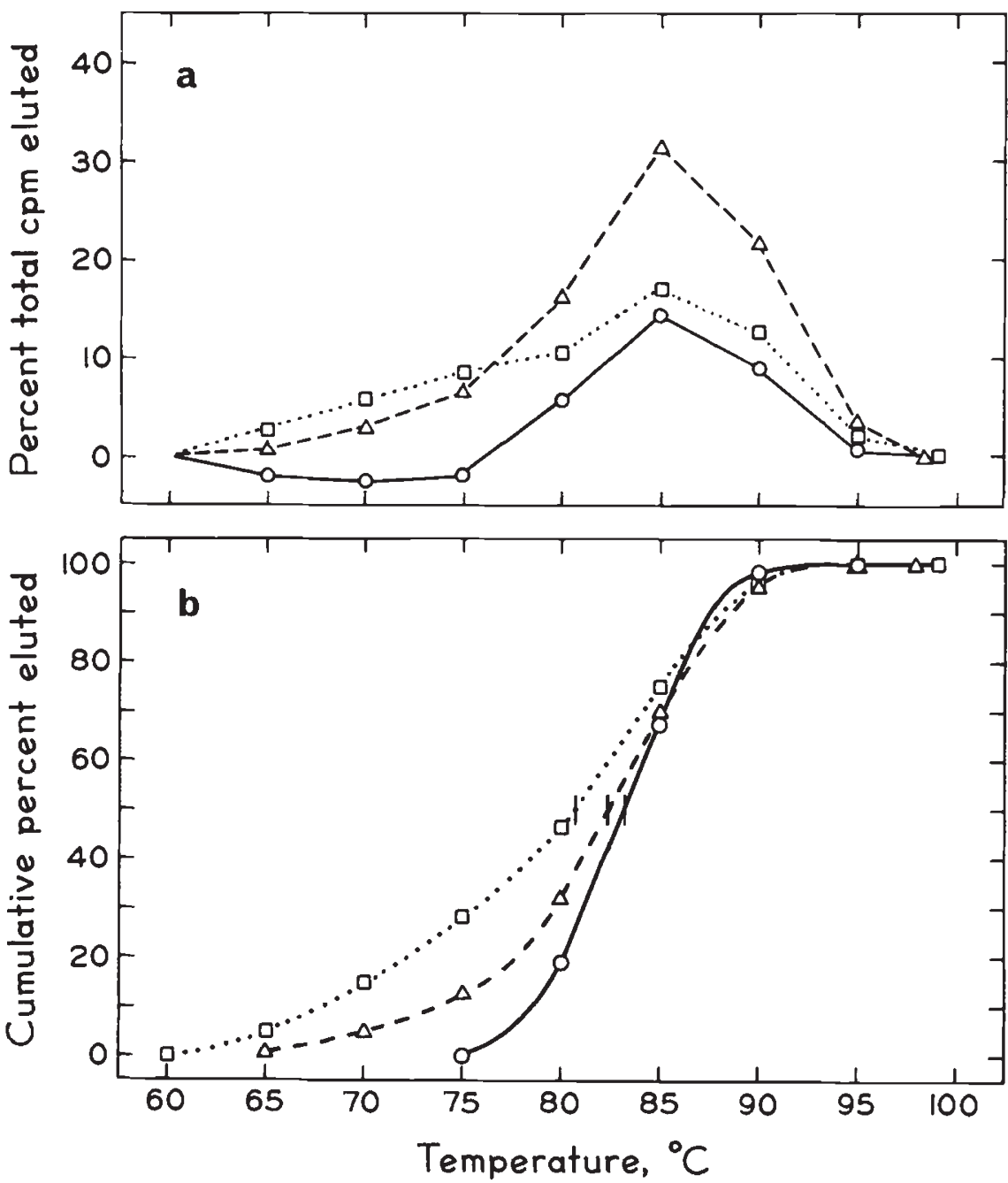

FIG. 2.-Thermal denaturation profiles of duplexes formed by ${ }^{14} \mathrm{C}-A$. serenana single copy tracer reassociated with excess total $A$. serenana DNA. Reassociation and thermal elution procedures are described in the text. $(\cdots \square \cdots)$, Profile of the single copy tracer-driver DNA duplexes formed by reassociation to equivalent Cot 880 . ( $--\Delta--)$, Profile of the duplexes formed by reassociation to ECot 28,000 . The profile for duplexes formed between equivalent $C$ t values of 880 and 28,000 ( $-\mathrm{O}-$ ) was obtained by subtraction as described in Methods. In panel A, denaturation results are graphed as the percent of total ${ }^{14} \mathrm{C}$-single copy tracer (HAP-bound and HAP-unbound fractions) eluted at each temperature. In Panel $B$, denaturation results are graphed as cumulative percent of HAP-bound ${ }^{14} \mathrm{C}$-single copy tracer eluted. The $T_{E}$ values for each curve are marked by vertical slashes. 
denaturation profile was subtracted from the $C_{0} t 28,000$ profile as illustrated in fig. 2. Profiles thus corrected reflect the thermal stability of only those hybrids formed with single copy kinetics. The efficacy of this procedure was shown by using hybridization kinetics to detect the presence of repeated or foldback sequence contaminants and thus predict the result of the correction. Where a single copy tracer contains repeated sequences, the correction should result in an increase in $T_{E}$ since repeated sequences (especially repeats remaining in single copy preparations isolated by kinetic fractionation) should form lower stability duplexes than single copy sequences. This effect is illustrated in figs. 2 and 3 . On the other hand, if a tracer contains foldback sequences, the correction procedure should reduce the $T_{E}$ by removing foldback duplexes. The majority of tracer profiles showed little or no change $\left( \pm 1^{\circ}\right)$ in $T_{E}$ when corrected by this procedure (table 1), indicating the purity and homogeneity of the tracer preparations. The few tracers showing a decrease of more than $1.5^{\circ}$ in $T_{E}$ after correction all contained significant percentages ( $c a .30$ per cent) of foldback sequences. Thus the correction procedure effectively removed repeated and foldback sequence contaminants from thermal stability profiles of homologous and heterologous tracer hybrids.

Table 1 lists both corrected and uncorrected $\Delta T_{E}$ values for all experiments. Corrected values were between $4 \cdot 0$ and $8 \cdot 2^{\circ} \mathrm{C}$. Except for the $A$. rosea $\times A$. serenana values (discussed below), all replicates fall within $1.5^{\circ}$ of each other. For reactions involving single copy DNA, reciprocal experiments (in which the same two tracers are reacted with driver DNA from one species in one reaction and with driver DNA from the second species in a second reaction) should give the same $\Delta T_{E}$ value. As can be seen in table 1 , reciprocal values also generally fall within $1.5^{\circ}$ of each other except for experiments involving spinach. So little hybridization occurred between spinach and Atriplex species (4-13 per cent after subtracting tracer duplexes formed before equivalent $C_{0} t 880$ ) that the differences in this case are not considered to be significant.

The $A$. rosea $\times A$. serenana $\Delta T_{E}$ replicate difference of $3 \cdot 0^{\circ} \mathrm{C}$ seems unexpectedly large (table 1 ). However, it is interesting that the $6.5^{\circ}$ average $\Delta T_{E}$ for these reactions closely matches the reciprocal average of $6 \cdot 7^{\circ}$. Thus the $3^{\circ}$ difference between replicates may simply represent an extreme case of normal variation, a conclusion which emphasizes the usefulness of both replicate and reciprocal reactions.

\section{Discussion}

\section{(i) Intergeneric hybrids}

Atriplex-spinach $\Delta T_{E}$ values show poor reciprocity, differing by as much as $4^{\circ}$. We believe this reciprocity failure is due to the small amount of intergeneric duplex formation. Not only does the total single copy sequence cross reaction involve just 10-20 per cent of the available sequences, but furthermore, corrected $\Delta T_{E}$ values are based on duplexes formed between only 4-13 per cent of the single copy sequences. However, it is interesting that the $\Delta T_{E}$ values determined for spinach-Atriplex single copy sequence hybrids fall into the same general range as those determined for the Atriplex interspecific hybrids. The small amount of intergeneric cross reactivity, 

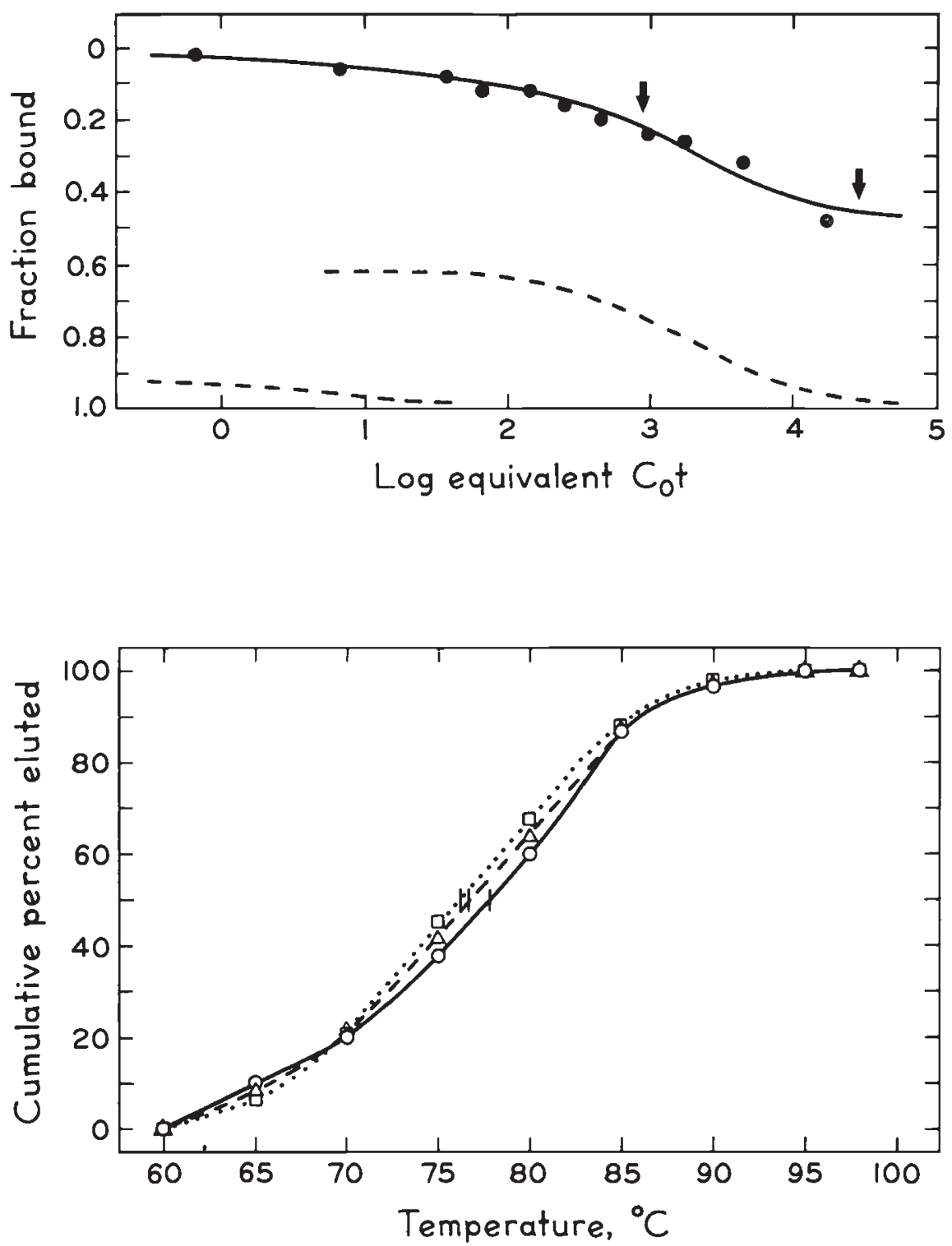

FIG. 3.-Reassociation kinetics and thermal denaturation profiles for the heterologous reaction between ${ }^{3} \mathrm{H}-A$. sabulosa single copy sequence tracer hybridized with $A$. serenana total DNA. Top Panel: Kinetic data were obtained and fit by the retarded rate procedure for heterologous tracers as described (Belford and Thompson, 1980). The data gave a best fit with two components. The faster, repeated sequence component comprises approximately 9 per cent of the reactable heterologous tracer preparation. Arrows indicate the $C_{0} t$ values to which tracer and driver DNAs were hybridized before thermal denaturation on HAP ( $E C_{0} t 880$ and 28,000). Note that the repeated sequence component is completely reacted before $E C_{0} t 880$. Bottom panel: Thermal denaturation of HAP-bound tracer-driver duplexes was performed as described in the text. Denaturation profiles of ${ }^{3} \mathrm{H}-A$. sabulosa DNA duplexes hybridized to $E C_{0} t 880(\cdots \square \cdots)$ or $E C_{0} t 28,000$ $(\cdots \Delta \cdots)$ with $A$. serenana driver DNA were used to obtain the denaturation profile of tracer-driver duplexes between these two $E C_{0} t$ values $\left(--O_{--}\right)$. 
TABLE 1

Corrected and uncorrected $\Delta T_{E}$ values

Homologous Tracer
A. rosea

A. rosea

A. rosea

A. rosea

A. rosea

A. rosea

A. rosea

A. rosea

A. rosea

A. rosea

A. serenana

A. serenana

A. serenana

A. serenana

A. serenana

A. serenana

A. serenana

A. serenana

A. serenana

A. serenana

A. serenana

A. serenana

A. fruticulosa

A. triangularis

A. sabulosa

A. hortensis

A. truncata

A. phyllostegia Spinach

A. phyllostegia $\ddagger$

A. truncata

Spinach $\ddagger$

\begin{abstract}
A. sabulosa
A. triangularis

A. truncata

A. phyllostegia

A. hortensis

A. serenana

A. serenana

A. fruticulosa

A. fruticulosa

Spinach
\end{abstract}

A. fruticulosa

A. fruticulosa

A. truncata

A. sabulosa

A. hortensis

A. phyllostegia

A. phyllostegia $\dagger$

A. rosea

A. rosea

A. rosea

A. triangularis

Spinach

A. rosea

A. rosea

A. rosea

A. rosea

A. rosea

A. rosea

A. rosea

A. serenana

A. serenana

A. serenana

$\overbrace{\begin{array}{ccc}\text { Eq. Cot } \\ 880 & \begin{array}{c}\text { Eq. Cot } \\ 28,000\end{array} \text { Corrected }\end{array}}^{\Delta T_{E},{ }^{\circ} \mathrm{C}^{*}}$

$\begin{array}{ll}678 & 3.7\end{array}$

$678 \quad 6 \cdot 2$

$778 \quad 5.5$

$878 \quad 3.2$

$778 \quad 4.5$

$578 \quad 5.0$

$678 \quad 4.7$

$578 \quad 5 \cdot 0$

$678 \quad 4.7$

$878 \quad 7 \cdot 4$

$177 \quad 1.5$

$877 \quad 3.0$

1078

277

177

377

1078

377

877

678

277

1078

678

678

678

778

778

787

878

1078

1078

1078
$4 \cdot 7$

$5 \cdot 7$

$5 \cdot 5$

$4 \cdot 5$

$5 \cdot 0$

$5 \cdot 2$

$4.4 \quad 5.5$

$5 \cdot 6 \quad 6 \cdot 2$

$6.3 \quad 8.0$

$4.7 \quad 5 \cdot 0$

$6 \cdot 1 \quad 7 \cdot 5$

$5.7 \quad 7 \cdot 0$

$7 \cdot 8 \quad 8 \cdot 2$

$2 \cdot 5 \quad 4.7$

$3.7 \quad 4.0$

$4.5 \quad 5 \cdot 0$

$\begin{array}{lll}4.5 & 4.7 & 5.0\end{array}$

$\begin{array}{lll}6.5 & 6.5 & 5 \cdot 2\end{array}$

$\begin{array}{lll}6.5 & 5.7 & 5.5\end{array}$

$\begin{array}{lll}-4.0 & -0.6 & 6.0\end{array}$

$\begin{array}{lll}5.7 & 6.5 & 6.5\end{array}$

$\begin{array}{lll}0.7 & 3.7 & 6.0\end{array}$

$\begin{array}{lll}7.7 & 7 \cdot 7 & 7.5\end{array}$

$\begin{array}{lll}5.0 & 6.5 & 8.2\end{array}$

$\begin{array}{lll}-3.6 & -2.5 & 4.4\end{array}$

$\begin{array}{lll}7.0 & 6.7 & 7.5\end{array}$

$\begin{array}{lll}7 \cdot 3 & 6.7 & 6.5\end{array}$

$\begin{array}{lll}4 \cdot 5 & 4 \cdot 2 & 4 \cdot 0\end{array}$

$\begin{array}{lll}5 \cdot 8 & 5 \cdot 7 & 5 \cdot 4\end{array}$

$\begin{array}{lll}6.7 & 6.2 & 6.5\end{array}$

$6.5 \quad 5.4 \quad 4 \cdot 2$

$5 \cdot 2 \quad 4 \cdot 5 \quad 4 \cdot 2$

$8 \cdot 6 \quad 8 \cdot 0 \quad 4 \cdot 7$

$3 \cdot 5 \quad 3 \cdot 8 \quad 4 \cdot 2$

$0 \quad 1 \cdot 0 \quad 6.0$

* Each value listed is the average of 3 replicate thermal elution profiles; standard deviations of replicate $T_{E}$ values in a single experiment averaged $<0 \cdot 2^{\circ} \mathrm{C}$. Corrected values were obtained by subtracting the low Cot profile from the high Cot profile as described in the text and fig. 2 .

$\dagger$ The $A$. phyllostegia tracer used in these reactions contained about 30 per cent foldback sequences.

$¥$ The spinach and $A$. serenana tracers in these reactions both contained about 30 per cent foldback.

together with the improbability of spinach and $A$. rosea, or spinach and $A$. serenana having shared a common ancestor as recently as $A$. rosea and $A$. serenana or other Atriplex species pairs, leads us to hypothesize that the sequences showing intergeneric cross reaction represent a subset of evolutionarily conserved single copy DNA. Complexity estimates for this class (approximately $3 \times 10^{7}$ NTP; see Belford and Thompson, 1980) are well within the reported range for messenger RNA complexities in many organisms (e.g., Kiper, 1979; Kamalay and Goldberg, 1980). A similarly conserved subset of single copy DNA in the rat and mouse genomes appears to be evolving at about the same rate as structural gene sequences (analyzed 
by comparing single copy DNA and $c$ DNA-DNA hybridizations at increasingly stringent reassociation criteria; Rosbash et al., 1975).

The Atriplex-spinach results raise an important question concerning the general utility of the DNA hybridization technique in phylogenetic studies. The use of hybrid thermal stability as an index of divergence time depends upon the assumption that base substitution proceeds at a constant rate in the DNAs being compared. When hybridization drops to such a low level that a small fraction of selectively conserved sequences could represent a major part of the hybrids formed, one must wonder whether the resulting $\Delta T_{E}$ can be compared with those for species showing higher levels of cross reaction.

(ii) Interspecific hybrids and phylogenetic considerations

Within the genus Atriplex, cross reactivities were generally about 50 per cent or more (Belford and Thompson, 1980), thus reducing the uncertainty in interpreting $\Delta T_{E}$ measurements. The only exception was found in experiments with $A$. phyllostegia single copy sequences, where only about 30 per cent of the tracer was able to pair with $A$. rosea or $A$. serenana DNA. Perhaps because of this limited cross reaction, a greater than average reciprocal difference was observed for the $A$. phyllostegia- $A$. rosea cross reactivities and $\Delta T_{E}$ measurements.

The $\Delta T_{E}$ data show the lowest amount of base sequence divergence between the species pairs $A$. serenana- $A$. fruticulosa and $A$. rosea$A$. sabulosa, a finding which agrees with the classical and experimental taxonomic evidence that these species are closely related pairs. Most other species pairs display $\Delta T_{E}$ values between 5 and $6.5^{\circ}$ in $75 \mathrm{mM}$ PB. These values would probably be about twice as high in $12^{\circ} \mathrm{mM}$ PB (see above and fig. 1). Thus the amounts of sequence divergence observed between Atriplex species are distinctly larger than intrageneric divergence values measured for species of sea urchin (Angerer et al., 1976; Harpold and Craig, 1978), deer mouse (Rice, 1972), Junco (Shields and Straus, 1975), black flies (Sohn et al., 1975) or salamander (Mizuno and MacGregor, 1974). Our divergence estimates for Atriplex are also greater than those reported for Lathyrus species (Narayan and Rees, 1977) and greater than or equal to those observed in the genus Osmunda (Stein et al., 1979). Indeed, it appears that sequence divergence within Atriplex is more comparable to previously observed in intergeneric values for animal DNA (Eden et al., 1978; Rice, 1972; Shields and Straus, 1975; Laird et al., 1969; Sohn et al., 1975). No intergeneric divergence estimates have been published for higher plants other than the spinach $\times$ Atriplex data reported here. As noted above, these are not considered comparable to the intrageneric Atriplex data because of the low level of cross reaction on which they are based.

All species in this study were compared with the same two reference species. Possible divergence time relationships which can be derived from these data therefore fall into only three categories: a given lineage may have originated before the separation of lines leading to the reference species, at the same time as this separation, or at some later time. If genetic isolation was a unique and permanent event in each case, and mutations have accumulatec at the same rate in different lines, then $\Delta T_{E}$ relationships should also fall into three classes. In the case of a lineage originating before the reference species, the $\Delta T_{E}$ to both references should be equal but 
TABLE 2

Summary of $\Delta T_{E}$ measurements

A

A. rosea

A. serenana

\section{Species}

B
A. sabulosa
A. triangularis
A. truncata
A. phyllostegia
A. hortensis
A. serenana
A. fruticulosa
Spinach
A. fruticulosa
A. truncata
A. sabulosa
A. hortensis
A. phyllostegia
A. rosea
A. triangularis
Spinach

\begin{tabular}{ccc}
\multicolumn{3}{c}{$\Delta T_{E},{ }^{\circ} \mathrm{C}$} \\
I & II & Difference \\
$4 \cdot 5$ & $4 \cdot 0$ & $0 \cdot 5$ \\
$5 \cdot 0$ & $6 \cdot 5$ & $1 \cdot 5$ \\
$5 \cdot 2$ & $6 \cdot 5$ & $1 \cdot 3$ \\
$5 \cdot 5$ & $4 \cdot 2$ & $1 \cdot 3$ \\
$6 \cdot 2$ & $5 \cdot 4$ & $0 \cdot 8$ \\
$6 \cdot 5^{*}$ & $6 \cdot 7^{*}$ & $0 \cdot 2$ \\
$7 \cdot 2^{*}$ & $7 \cdot 5$ & $0 \cdot 3$ \\
$8 \cdot 2$ & $4 \cdot 2$ & $4 \cdot 0$ \\
$4 \cdot 3^{*}$ & - & - \\
$5 \cdot 0$ & $4 \cdot 2$ & $0 \cdot 8$ \\
$5 \cdot 0$ & - & - \\
$5 \cdot 2$ & - & - \\
$5 \cdot 7^{*}$ & $4 \cdot 7$ & $1 \cdot 0$ \\
$6 \cdot 7^{*}$ & $6 \cdot 5^{*}$ & $0 \cdot 2$ \\
$8 \cdot 2$ & - & - \\
$4 \cdot 4$ & $6 \cdot 0$ & $1 \cdot 6$
\end{tabular}

In column I, the $\Delta T_{E}$ values were obtained by comparing $T_{E}$ values of single copy sequences of species $A$ and $B$ reassociated with total DNA of species $A$. In column II, the $\Delta T_{E}$ values were obtained from reciprocal reactions, that is, by comparing $T_{E}$ values of species $\mathrm{A}$ and $\mathrm{B}$ single copy sequences reassociated with total DNA of species B. The differences between reciprocal values are listed in the third column. All data are corrected values. $\left({ }^{*}\right)$ indicates averages from two or more independent experiments.

greater than that between the reference species themselves. Species whose origin was contemporary with that of the references should also have equal $\Delta T_{E}$ values to each reference, but they should be the same as the $\Delta T_{E}$ between references. When a given lineage originated from one of the reference lines later in evolution its $\Delta T_{E}$ to that reference should be small compared to the $\Delta T_{E}$ observed with the other reference (which should still be equal to that between the references themselves).

These theoretical $\Delta T_{E}$ relationships are indicated by the heavy solid lines in the matrix diagram of fig. 4 . The two arcs define points equidistant from each reference. Where these arcs intersect, the $\Delta T_{E}$ for each reference is the same as that between references. Dashed lines and circles have been used to indicate a $1^{\circ}$ range of experimental error. Given this range all the Atriplex species can be considered to fit the predicted pattern for simple divergence relationships (although the fit for $\boldsymbol{A}$. triangularis and $\boldsymbol{A}$. sabulosa is only marginal; see below). A. phyllostegia and $\boldsymbol{A}$. hortensis are located close to the intersection point, indicating they they became isolated from the $\boldsymbol{A}$. rosea and $A$. serenana lines at about the same time as or shortly after these lineages separated from each other. The $A$. truncata lineage may have originated at about this time or perhaps somewhat later, while the placement of the $\boldsymbol{A}$. fruticulosa range across the $\boldsymbol{A}$. serenana leg of the matrix clearly suggests that $\boldsymbol{A}$. fruticulos $a$ diverged from $\boldsymbol{A}$. serenana after the $\boldsymbol{A}$. serenana line had separated from that of $A$. rosea.

The overlap of $A$. triangularis and $A$. sabulosa ranges with that of the $A$. rosea leg might also be interpreted to suggest that these species diverged from the $A$. rosea lineage after the $A$. rosea and $A$. serenana lines had 


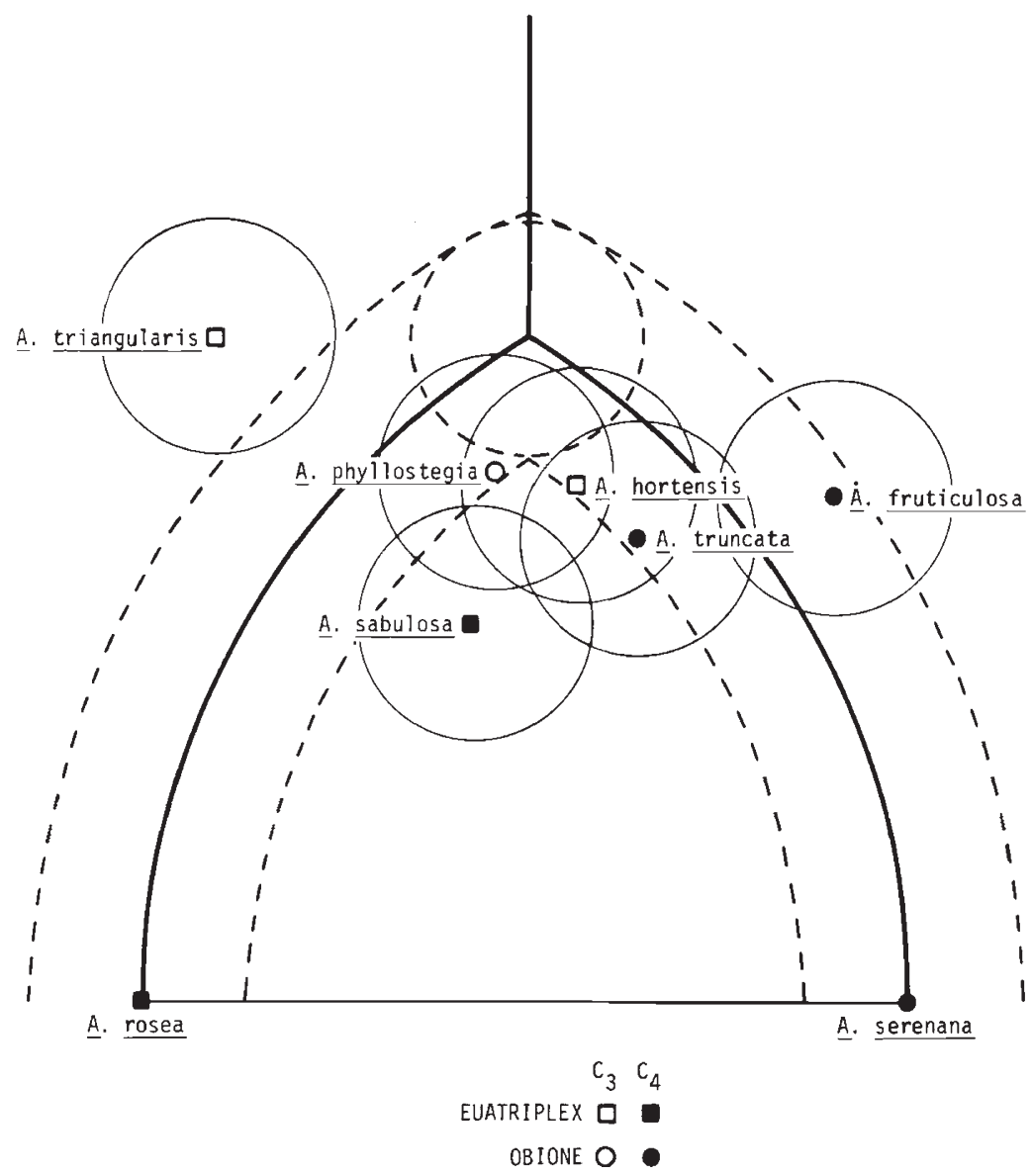

FIG. 4.-Location of the Atriplex species on the theoretical matrix described in the text. Linear distances from the reference species $(\boldsymbol{A}$. rosea or $\boldsymbol{A}$. serenana) are proportional to the average corrected $\Delta T_{E}$ values. Circles and dashed lines indicate a $\pm 1^{\circ}$ error range.

become independent. However, these overlaps are not great, which leads us to consider an alternative hypothesis involving secondary exchanges of genetic material. It may be that the $A$. triangularis line originated before the separation of $A$. serenana and $A$. rosea. At some later time, secondary gene exchange may have occurred between $A$. triangultris and $A$. rosea, reducing the apparent base-sequence divergence measurable for this species pair. Similarly, the $A$. sabulosa ancestor may have retained the ability to interbreed with both $A$. rosea and $A$. serenana lines for some time after the separation of the latter two species, so that the divergence between $A$. sabulosa and either reference appears to be less than the divergence between the references themselves.

Secondary gene exchange might occur by introgressive hybridization, as has been documented in many higher plant groups (Heiser, 1973), including Atriplex (Osmund et al., 1980). Support for such an hypothesis comes from sexual hybridization data (Björkman et al., 1973; Nobs, 1976) demonstrating the ability of both $A$. sabulos a and $A$. triangularis to form partially fertile 
hybrids with $A$. rosea. Similarly successful sexual hybridizations were not obtained for other species used in our study except $\boldsymbol{A}$. fruticulosa and $\boldsymbol{A}$. serenana.

Phylogenetically, the introgression hypothesis parallels the simple divergence scheme in suggesting that the species near in the center of the diagram- $A$. hortensis, $A$. truncata and $A$. phyllostegia-represent lineages which arose at about the same time as those of $A$. serenana and $A$. rosea. Both hypotheses assume that $A$. triangularis and $A$. sabulosa have been fully separated from $A$. serenana for a longer time than from $A$. rosea, while $A$. fruticulosa has been isolated for a longer time from $A$. rosea than from $A$. serenana. The evolutionary mechanisms are at odds only on the question of whether a single and permanent divergence event has occurred.

Our hybrid thermal stability measurements indicate that lines leading to many present-day Atriplex species probably originated during a single period of rapid speciation. This group includes $A$. rosea, $A$. serenana, $A$. hortensis, $A$. phyllosetegia, and perhaps $A$. truncata; $A$. triangularis may have originated even earlier. Even the first four species, whose placement is most certain, include representatives of both subgenera. Thus, the subgeneric distinction proposed by Hall and Clements (1923), with its implication of a gradually reticulating phylogenetic "tree," is not supported by our data. Furthermore, since the same four species also include representatives of both $\mathrm{C} 3$ and $\mathrm{C} 4$ photosynthetic pathways, it appears logical to assume that $\mathrm{C} 4$ photosynthesis first appeared in Atriplex at about this time. In the context of the phylogenetic history derived from our molecular data, it is no longer necessary to postulate a polyphyletic origin for $\mathrm{C} 4$ photosynthesis within Atriplex.

If it is assumed that plant DNA base sequences diverge at rates comparable to those for animals, it is possible to construct an approximate time scale for Atriplex evolution. Estimates for base substitution rates in animal genomes mostly fall between 0.06 and 0.3 per cent per million years (Laird et al., 1969; Fitch, 1976; Fitch and Langley, 1976; Kohne, 1970; Harpold and Craig, 1978; Angerer et al., 1976; Galau et al., 1976). We assume that a $1^{\circ} \Delta T_{E}$ in the present experimental system corresponds to about 2 per cent base pair mismatch in interspecific hybrids, or about 1 per cent base substitution per lineage. Thus the $\Delta T_{E}$ of $6 \cdot 5^{\circ}$ between $A$. rosea and $A$. serenana would indicate about 6.5 per cent substitution in each genome. If we use a rate of 0.2 per cent substitution per million years, the major period of active speciation in Atriplex would have been roughly 30-35 million years ago. On the same basis, $A$. fruticulosa would have diverged from $A$. serenana about 20 million years ago. These estimates would place the major Atriplex speciation events in the Oligocene-Miocene epochs of the Tertiary period of geologic history. Although extremely tentative, this placement is not unreasonable in light of existing fossil and geologic evidence that with the recession of forested land, herbaceous plants were becoming increasingly abundant during the Oligocene, Miocene, and Pliocene epochs. Furthermore, since fossil evidence for $\mathrm{C} 4$ plants has been found in Miocene and Pliocene formations (Thomasson, 1978; Nambudiri et al., 1978), it can be assumed that environmental conditions at that time were right for the appearance of $\mathrm{C} 4$ adapted species. 


\section{REFERENCES}

ANGERER, R. C., DAVIDSON, E. H., AND BRITTEN, R. J. 1976. Single copy DNA and structural gene sequence relationships among four sea urchin species. Chromosrma, 56, 213-226.

BELFORD, H. S. 1979. Single copy DNA sequence comparisons within the genus Atriplex. Ph.D thesis, University of Massachusetts (Amherst).

BELFORD, H. S., AND THOMPSON, w. F. 1980. Single copy DNA homologies in Atriplex. I. Cross reactivity estimates and the role of deletions in genome evolution.

BJÖRKMAN, O., TROUGHTON, J., AND NOBS, M. A. 1973. Photosynthesis in relation to leaf structure. Brookhaven Symp. in Biology, 25, 206-226.

BRITTEN, R. J., GRAHAM, D. E., AND NEUFELD, B. R. 1974. Analysis of repeating DNA sequences by reassociation. Methods in Enzymology, 29, 363-418.

EDEN, F. C., HENDRICK, J. P., AND GOTTLIEB, S. S. 1978. Homology of single copy and repeated sequences in chicken, duck, Japanese quail and ostrich DNA. Biochemistry, 17, 5113-5121.

FITCH, w. M. 1976. Molecular evolutionary clocks. In Molecular Evolution, ed. F. J. Ayala, pp. 160-178. Sinauer Assoc., Inc. Sunderland, Mass.

FITCH, W. M., AND LANGleY, C. H. 1976. Protein evolution and the molecular clock. Fed. Proc., 35, 2092-2097.

GALAU, G. A., CHAMBERLINE, M. E., HOUGH, B. R., BRITTEN, R. J., AND DAVIDSON, E. H. 1976. Evolution of repetitive and nonrepetitive DNA. In Molecular Evolution, ed. F. J. Ayala, pp. 220-224. Sinauer Assoc., Inc. Sunderland, Mass.

hall, H. M., AND ClementS, F. E. 1923. The genus Atriplex. In The North American Species of Artemisia, Crysothamnus, and Atriplex. Carnegie Inst. of Wash. Publ. 326, pp. 235-342. Judd and Detweiler, Inc., Washington, D.C.

HARPOLD, M. M., AND CRAIG, S. P. 1978. The evolution of nonrepetitive DNA in sea urchins. Differentiation, 10, 7-11.

HEISER, C. B. 1973. Introgression re-examined. Bot. Rev., 39, 347-366.

KAMALAY, J. C., AND GOLDBERG, R. B. 1980. Regulation of structural gene expression in tobacco. Cell, 19, 935-946.

KIPER, M. 1979. Gene numbers as measured by single-copy DNA saturation with mRNA are routinely overestimates. Nature, $278,279-280$.

KOHNE, D. E. 1970. Evolution of higher organism DNA. Quart. Rev. Biophysics, 33, 327-375.

LAIRD, C., MCCONAUGHY, B. G., AND MCCARTHY, B. J. 1969. Rate of fixation of nucleotide substitution in evolution. Nature, 224, 149-154.

MARTINSON, H. G., AND WAGENAAR, E. G. 1977. Thermal elution chromatography of nucleic acids on hydroxyapatite. Analytical Biochem., 61, 144-154.

MIZUNO, S. AND MACGREGOR, H. C. 1974. Chromosomes, DNA sequences, and evolution in salamanders of the genus Plethodon. Chromosoma, 48, 239-296.

NAMBUDIRI, E. M., TIDWELL, W. D., SMITH, B. N., AND HEBBERT, N. P. 1978. A C4 plant from the Pliocene. Nature, 276, 816-817.

NARAYAN, R. K. J., AND REES, H. 1977. Nuclear DNA divergence among Lathyrus species Chromosoma, 63, 101-107.

NobS, M. A. 1976. Hybridization in Atriplex. Carnegie Inst. Wash. Yearbook, 75, 421-423.

OSMOND, C. B., BJÖRKMAN, O., AND ANDERSON, D. J. 1980. Physiological processes in plant ecology: Towards a synthesis with Atriplex. In Ecological Studies, Volume 36. Springer-Verlag, New York.

RICE, N. 1972. Changes in repeated DNA in evolution. Brookhaven Symp. Biol. 23, 44-78.

ROSBASH, M., CAMPO, M. A., AND GUMMERSON, K. S. 1975. Conservation of cytoplasmic poly $(\mathrm{A})$-containing RNA in mouse and rat. Nature, 258, 682-686.

SHIELDS, G. F., AND STRAUS, N. A. 1975. DNA-DNA hybridization studies of birds. Evolution, 29, 159-166.

SOHN, U.-I., ROTHFELS, K. H., AND STRAUS, N. A. 1975. DNA : DNA hybridization studies in black flies. J. Mol. Evol. 5, 75-85.

STEIN, D. B., THOMPSON, W. F., AND BELFORD, H. S. 1979. Studies on DNA sequences in the Osmundaceae. J. Mol. Evol., 13, 215-232.

THOMASSON, J. R. 1978. Epidermal patterns of the lemma in some fossil and living grasses and their phylogenetic significance. Science, 199, 975-977. 
ULLMAN, J. S., AND MCCARTHY, B. J. 1973. The relationship between mismatched base pairs and thermal stability of DNA duplexes. II. Effects of deamination of cytosine. Biochim. Biophys. Acta, 294, 416-424.

WILSON, A. C., CARLSON, S. S., AND WHITE, T. J. 1977. Biochemical evolution Ann. Rev. Biochem., 46, 573-639. 